\title{
Effect of Rapping System Malfunctions on ESP Performance
}

\section{Tushar Kumar}

\begin{abstract}
In an attempt to improve Electrostatic precipitator (ESP) performance, the functioning of rapping system plays a vital role. Malfunctioning of rapping system will lead to reentrainment of fly ash into the gas stream and back corona in some cases. Proper upkeep of Rapping system and optimization of rapping frequency will lead to minimise reentrainment as well as avoidance of back corona. This paper explains various factors associated with Rapping system malfunctioning, its impact on ESP performance, identification of issues and ways to address issues related to ash removal from collecting plates. Some of the issues can be identified using V-I curve analysis while others can be identified by visual inspection during shut down of ESP.
\end{abstract}

Keywords: ESP performance Rapping system V-I Curve Back corona

\section{INTRODUCTION}

The electrostatic precipitation process consists of following fundamental steps [1].

I. Particle Charging

II. Particle Migration and Collection on electrode

III. Removal of the collected dust from Collecting Electrode

IV. Removal from Hopper

The particulate must be charged for the electric field to support driving force towards collection electrodes. Particle charging in ESP is accomplished by corona discharge by emitting electrodes through the application of high voltage. To achieve efficient precipitation, the precipitator requires adequate corona generation for effective charging and sufficient voltage to produce an electric field for precipitating charges particles. Fundamentally an electrically charged particle is acted upon by electric field based on the polarity of charge and field strength and direction.

After charging, particulate moves towards collecting electrode with migration velocity. Theoretically, migration velocity is proportional to the radius of particle squared and electric field squared / voltage squared.

For effective precipitation, ESP is dependent on high voltage, enough to produce an electric field to precipitate the particles and have sufficient current capability to meet ion requirement for charging of particles.

The collected particle on electrode needs to be removed for facilitation of collection of subsequent particulate matter. In dry type ESPs particle is held on collecting plate by a combination of electrostatic, mechanical and molecular forces until a layer of sufficient thickness is built-up. This layer is dislodged from collecting plate by providing a mechanical shear force through rappers into hoppers. From hoppers, it is removed by wet slurry evacuation or dry extraction process.

All the above process can be considered as a series element of a network if one element develops performance issue it will impact the overall collection efficiency.

\section{RAPPING SYSTEM}

Following deposition on the collection surface, the material must be removed from the precipitator in such a manner to prevent or minimizes its reintroduction into the gas stream. In dry type ESPs the particulate is collected dry and is held on the plates by a combination of Electrostatic, Mechanical and molecular forces until a layer of sufficient thickness builds up at which time the collection plate is rapped to cause the dust to fall in layers or agglomerates into the dust collection hoppers. Rapping systems for both collection and discharge electrodes can be of the impact or vibrator type. Impact rappers are normally actuated pneumatically, electrically, or by gravity, and rapping can vary from a single blow to a rapid succession of impacts. The rapping cycle can be varied over a wide range depending upon the requirements of the precipitator. Vibrator types are generally motor-driven vibrators that shake the electrode support structure and are often used on the discharge electrode in conjunction with an impact rapper on the collection plate. Here in this paper, problems related to impact hammers has been discussed.

Rapping systems are provided for collecting and emitting electrodes.(Fig. $1 \& 2$ ) Most of these system are tumbling hammer type. Geared motors drive these rappers. These hammers are positioned at an angular displacement of 195-210 degree. Tumbling hammers are mounted on a horizontal shaft. As the shaft rotates slowly, the hammers tumble on to the shock bar/ beam which transmits the blow to electrodes. One complete revolution of shaft covers the entire field. 


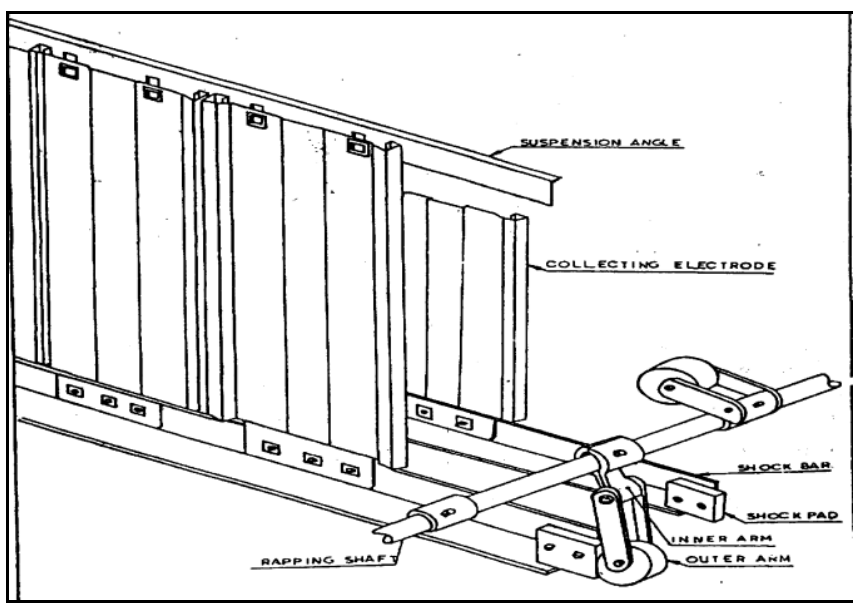

Fig. 1. Rapping Arrangement- Collecting Electrode

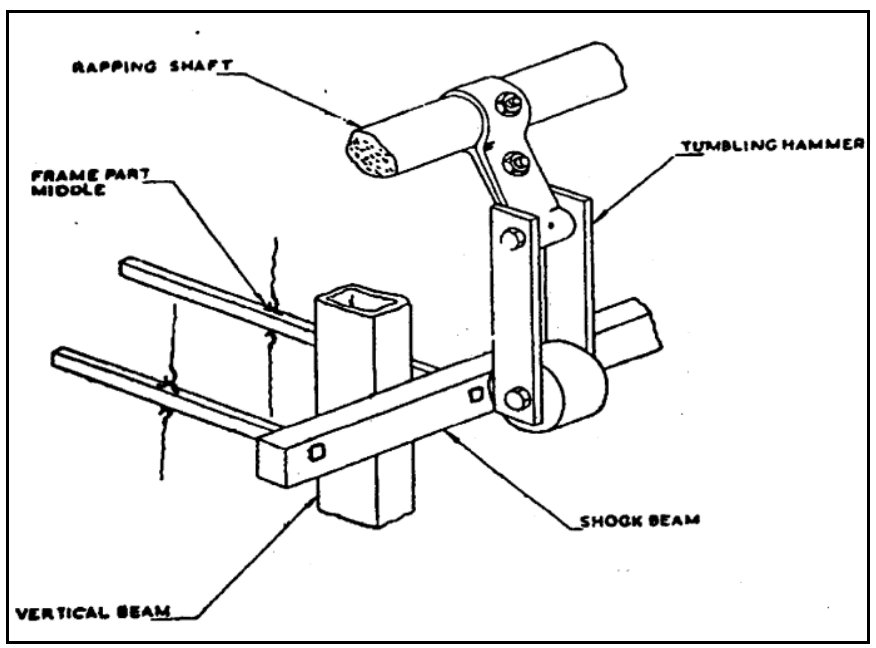

Fig. 2. Rapping Arrangement- Emitting Electrode

\section{FACTORS EFFECTING RAPPING SYSTEM PERFORMANCE}

Following deposition on the collection surface the material must be removed from the precipitator in such a manner to prevent or minimizes its reintroduction into the gas stream. Following factors affect the removal of the collected dust from Collecting Electrode.

\section{A. High Resistivity of ash [4]}

The dust layer as a whole is held to the collection surface by electrical forces, and by cohesive and van der Waals' forces between the surface of the collection plate and the particles comprising the dust layer. Electrical forces are generally large, and in the case of high resistivity dust, can be so large as to make removal difficult.

Electrical forces holding the dust layer have been studied by Penney and Klingler [1]. The magnitude of the electrical forces is given by.

$$
\mathrm{F}=\left(\mathrm{C}_{0} / 2\right)\left[\left\{\mathrm{j} \rho \mathrm{C} 1 / \mathrm{\epsilon}_{0}\right\}^{2}-\{(\mathrm{V}-\mathrm{j} \rho \mathrm{t}) /(\mathrm{s}-\mathrm{t})\}^{2}\right]
$$

where, $\epsilon_{0^{-}}$Permittivity of free space, $E 1$ Permittivity of dust layer, j - Current density, $\rho$ - Dust Resistivity, $\mathrm{v}$ - Voltage, $\mathrm{t}$ - Dust layer thickness, $\mathrm{s}$ Interelectrode spacing

The electrical force has two components. The first term in the equation is the electrostatic components of force due to the build up of negative charges on the surface of the dust layer.
The second term is due to the electric field within the dust layer. For most dust, the electrical resistivities are sufficiently high that the electrical forces are in a direction to force the dust layer to the collecting electrode.

The efficiency of rapping, measured in terms of residual dust, is in general improved if the power is removed during the rap. This is due to the removal of the corona current and the reduction of the force holding the dust layer to the plate. Since this force is dependent on resistivity, its magnitude will vary for different types of dust and the requirement for power-off rapping will depend on the dust characteristics. Power-off rapping is usually resorted to only in the event the usual rapping practices cannot be followed.

\section{B. Reentrainment of Flyash}

Reentrainment of flyash [4] into gas stream is dependent on the frequency of blow, ash layer thickness on plates, acceleration imparted to plate by blow, gas velocity in ESP, Cohesive property of flyash etc. It has been observed that due to worn out tumbling hammers, shock pads, restricted movement of collecting plates due to fouling with guide bars and misalignment of rapping hammers with other components are major reasons for reduced acceleration to collecting plates. The acceleration required varies with the type of dust and with whether the electrode is rapped in the plane of the electrode (shear) or perpendicular to the plane (normal).

If sufficient amount of flyash is not allowed to build upon collecting electrode, it is likely to be carried back into gas stream upon rap. Cohesive property of flyash plays an important role in reentrainment phenomenon. Ammonia dosing has been observed to improve the cohesive property of ash due to the formation of Ammonium Bi sulphate which is sticky in nature leads to a reduction in reentrainment.

\section{USE OF VOLTAGE - CURRENT CHARACTERISTICS TO IDENTIFY RAPPING ISSUES}

The voltage-current relationships of an ESP are governed by the mechanical design of the ESP, the size and concentration of dust particles in the gas stream, the presence of a dust layer on collection electrode, temperature and composition of the gas stream. However rapping system issues like heavy ash build up on collecting plates or presence of back corona can be identified use of V-I curves[2] (Fig. 3) also. 


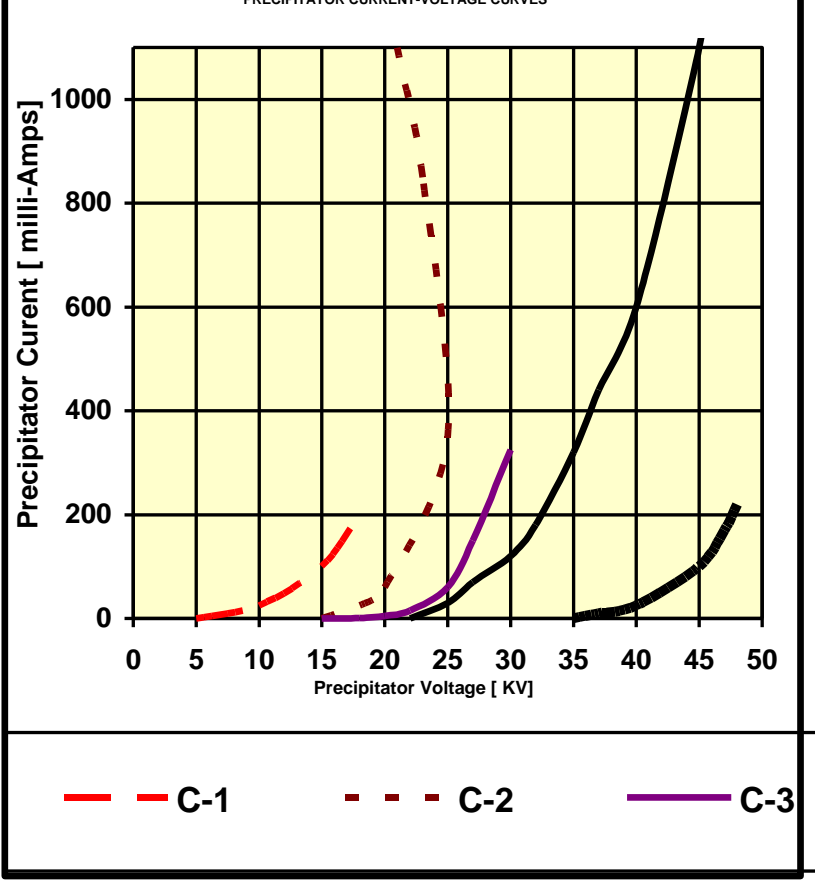

Fig. 3. V-I curve under various condition

- C-1: This curve illustrates severely reduced clearance which is likely to be due to severe misalignment between the emitting electrodes and collecting electrode or any earthed section of the ESP. One of the reasons for reduced clearance can be excessive ash build up also.

- C-2: This curve indicates severe Back Corona caused by high dust resistivity. This curve is usually associated with high resistive ash wherein collected charged particle is unable to lose charge and give rise to the production of positive charges which in turn lead to neutralization of negative charges thereby deteriorating the ESP performance considerably.

- C-3: This curve indicates spark-over at lower average voltages due to Back Corona thereby reducing the minimum voltage between peaks or indicative of reduced clearance between the emitting electrodes and any earthed section of ESP.

- C-4: This curve indicates the effect of heavy dust deposits on the emitter electrodes. The corona starting voltage is abnormally high due to the increase in the effective radius of the emitting electrodes. Breakdown voltage is reached at significantly lower voltage.

\section{V-I CURVE ANALYSIS (ANALYSIS \& RESULT)}

All illustrations (photographs, drawings, graphs, etc.), not including tables, must be labelled "Figure." Figures must be submitted in the manuscript. All tables and figures must have a caption and/or legend and be numbered (e.g., Table 1, Figure 2), unless there is only one table or figure, in which case it should be labelled "Table" or "Figure" with no numbering. Captions must be written in sentence case (e.g., Macroscopic appearance of the samples.). The font used in the figures should be Times New Roman, normal, size 8. If symbols such as $\times, \mu, \eta$, or $v$ are used, they should be added using the Symbols menu of Word.
V-I curves are the tool to identify ESP performance issues online. Apart from other abnormalities, the V-I curve may indicate rapping system issues also. In one of the ESP, detailed analysis of ESP voltage and current data was performed and 10 fields were identified for analysis. V-I curves were drawn in increment of around $5 \mathrm{KV}$. On analysis of V-I curve, it was suspected to have back corona issue affecting the majority of fields. Power down rapping was done to remove ash deposited in all 10 fields. After doing Power down rapping normal voltage and the current was restored in 5 fields with an increase in Peak voltages. Marginal Improvement was observed in 3 more fields (3, 4 $\& 5$ ). In 2 fields ( $1 \& 2$ ) not much improvement observed. In these 2 fields, it was suspected that either reduced clearance between electrodes or rapping system issue was suspected. During overhauling these 5 fields were inspected thoroughly. In field 1, rapping hammers were hitting the support bar before hitting shock pads due to worn out hinges of hammers thus losing the intensity of impact on collecting electrode. In the field, no 2 one shock pad was missing and heavy dust deposit was observed leading to reduced clearances. In remaining three fields (3, 4 \& 5), restricted movement of few collecting electrode plates was observed leading to a reduction in the impact of rapping hammers. In field 4 corona initiation voltage was more than $35 \mathrm{KV}$ indicating the possibility of ash builds up on emitting electrodes which were also confirmed during the inspection.

Table 1: Secondary Voltage \& Current before and after performing V-I curve analysis

\begin{tabular}{|c|c|c|c|c|c|c|c|c|}
\hline Fielc & & Befor & & & & & & \\
\hline & $\begin{array}{c}\text { Ave } \\
\text { rag } \\
\mathrm{e} \\
\text { Volt } \\
\text { age } \\
\text { (Kv) }\end{array}$ & $\begin{array}{c}\text { Avera } \\
\text { ge } \\
\text { Curre } \\
\text { nt } \\
\text { (MA) }\end{array}$ & $\begin{array}{l}\text { Valley } \\
\text { Volta६ } \\
\text { e (Kv) }\end{array}$ & $\begin{array}{l}\text { Peak } \\
\text { Volt } \\
\text { age } \\
(\mathrm{Kv})\end{array}$ & $\begin{array}{l}\text { Avera } \\
\text { ge } \\
\text { Volta } \\
\text { ge } \\
\text { (Kv) }\end{array}$ & $\begin{array}{c}\text { Aver } \\
\text { age } \\
\text { Curre } \\
\text { nt } \\
\text { (MA) }\end{array}$ & $\begin{array}{c}\text { Vall } \\
\text { ey } \\
\text { Volt } \\
\text { age } \\
\text { (Kv) }\end{array}$ & $\begin{array}{c}\text { Pea } \\
k \\
\text { Volt } \\
\text { age } \\
\text { (Kv) }\end{array}$ \\
\hline 1 & 38 & $\begin{array}{c}23 \\
6\end{array}$ & 31 & 54 & 36 & $\begin{array}{c}26 \\
6\end{array}$ & 29 & 53 \\
\hline 2 & 42 & 00 & 40 & 43 & 44 & $\begin{array}{c}07 \\
9\end{array}$ & 40 & 49 \\
\hline 3 & 37 & 00 & 37 & 38 & 43 & $\begin{array}{c}20 \\
7\end{array}$ & 39 & 51 \\
\hline 4 & 37 & $\begin{array}{c}02 \\
0\end{array}$ & 31 & 39 & 41 & $\begin{array}{c}17 \\
7\end{array}$ & 41 & 47 \\
\hline 5 & 00 & 00 & 00 & 00 & 32 & $\begin{array}{c}32 \\
5\end{array}$ & 27 & 46 \\
\hline
\end{tabular}

Published By: 

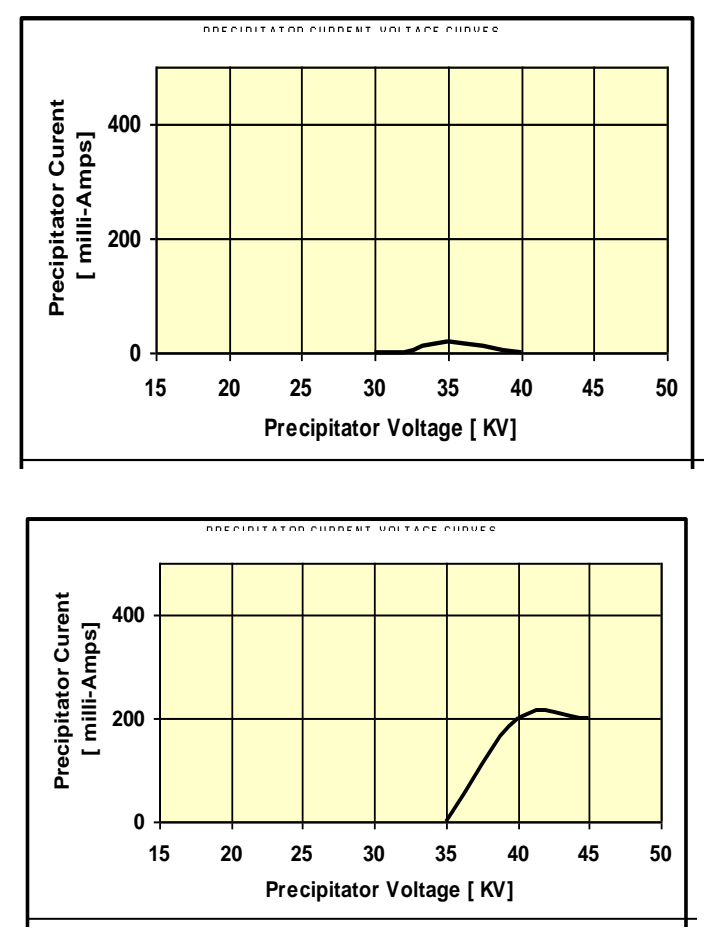

Fig. 4. V-I Curve for the field $3 \& 4$

\section{CONCLUSION}

1) Optimization of rapping conditions is essential if high collection efficiencies are to be maintained. This means that both the intensity of the rap and frequency of the rapping cycle must be optimum to give the minimum loss. In some instances, especially with tumbling hammer type rappers, located within the precipitator shell, the only adjustment possible is the frequency of the rapping cycle, since the intensity of the rap is fixed. Rapping system issues may also lead to the initiation of Back Corona in ESPs. By using the $\mathrm{V}$-I curve, Back corona arising out of rapping issues can be identified and dealt accordingly during shut down.

\section{REFERENCES}

[1] Electrostatic Precipitation by Sabert Oglesby, Jr. and Grady B. Nichols, Marcell Dekker Inc, New York.

[2] Electrical Operation of Electrostatic Precipitators by Ken Parker, IEE London.

[3] Electrostatic Precipitators, James H. Turner,Phil A. Lawless, Toshiaki Yamamo to David W. Coy, Research Triangle Institute, Research Triangle Park, NC 27709.

[4] ESP Design and Industrial Applications by Kjell Porle, ICESP XIII, Bangalore. 